\title{
The Airway App
}

\section{Laura Duggan / Pendar Labs. Available for iOS and Android, free download, 7.3 MB.}

\author{
D. John Doyle, MD, PhD
}

Received: 3 July 2016/Accepted: 23 July 2016/Published online: 27 July 2016

(C) Canadian Anesthesiologists' Society 2016

A novel idea, the Airway App allows clinicians to submit anonymous information on two important subjects: awake tracheal intubation and surgical airway events. Available in iOS, Android, and Web versions, the App uses crowdsourcing and data sharing to catalog what techniques work best "in a variety of REAL clinical circumstances by REAL clinicians." The resulting data are to be published on the App's website every two months. Note that the data custodians collect neither clinician nor patient identifiers, thereby eliminating privacy concerns.

I was able to download and install the App on my iPhone 6 without difficulty and, similarly, encountered no problems when trying the online version at http://www. airwaycollaboration.org/. This website also provides some limited information about awake intubation and surgical airways as well as offering a blog, a literature corner, and other helpful items.
This App is a truly valuable undertaking that I expect will advance the art and science of clinical airway management in important ways. For example, it could provide ideas and insights for the next generation of difficult-airway algorithms.

My only complaint is that, although the title suggests that the site is a place to learn about airway management, it is not its primary mission. Perhaps the App should be called "The Airway Case Reporting App." Nevertheless, the reader may consider it highly recommended.

Conflicts of interest None declared.

Editorial responsibility This submission was handled by Dr. Philip M. Jones, Associate Editor, Canadian Journal of Anesthesia. 